\title{
As brincadeiras infantis em comunidade periférica da cidade de Maceió-AL:
}

\author{
As relações de gênero em questão
}

\begin{abstract}
Alana Madeiro de Melo BARBOZA, Universidade Federal de Alagoas Paula Orchiucci MIURA, Universidade Federal de Alagoas

Adélia Augusta Souto de OLIVEIRA, Universidade Federal de Alagoas Heliane de Almeida Lins LEITÃO, Universidade Federal de Alagoas
\end{abstract}

Conhecer a experiência de brincar e as brincadeiras das crianças, assim como as redes de sociabilidade que (re)produzem as relações de gênero, são relevantes para estudos sobre infância e gênero. Diante disso, objetivou-se analisar os estereótipos e as relações de gênero, através de momentos lúdicos com crianças na pré-escola. Trata-se de uma pesquisaação de abordagem qualitativa desenvolvida por meio de oficinas lúdicas com 20 crianças entre 5 e 6 anos em comunidade periférica da cidade de maceió. Foi utilizada a análise de conteúdo dos dados advindos dos diários de campo e das produções infantis. Foram criadas quatro categorias temáticas: "bela, recatada e do lar?”; “o direito da expressão da agressividade é somente dos meninos?”; "contradições às imposições de gênero"; e "a dimensão social do brinquedo". Conclui-se que o ato de brincar, reproduz papéis esteriotipados de gênero, os quais são estruturados, por meio de significados culturais compartilhados entre os grupos em que as crianças pertencem e perpassam por um repertório daquilo que lhes é ofertado como possibilidade de brinquedos. Porém, apesar da pré-existência de significados impostos nas relações de gênero, o processo criativo da brincadeira tem a potencialidade de superação dessas desigualdades cristalizadas.

PALAVRAS-CHAVE: Brincar. Cultura. Brinquedos. Gênero. Infância. 


\section{Gênero, cultura e o brincar na infância}

A compreensão acerca dos corpos sexuados é construída por meio de estruturas discursivas e simbólicas que constituem a naturalização da existência da ideia de sexo como "verdadeiro", não sendo assim, um entendimento produzido de forma direta, universal e a-histórica (FOUCAULT, 1982). Em consonância com esse pensamento, aponta-se a afirmação de Coelho (2018) gênero não deve ser encarado como algo estático e amparado unicamente pela biologia. Tomando como base a teoria de Butler, Coelho (2018) afirma que gênero seria então:

[...] uma construção a partir da cultura não sendo algo que está acabado, estando constantemente em construção através do tempo, constituindo um fenômeno inconstante e contextual [...] e sendo um construto cultural depende da realidade que nos cerca (p.17).

Na teoria winnicottiana (2019), o autor apresenta a ideia sobre a constituição da corporeidade de cada sujeito. Sobre isso, Winnicott aponta que independente de sexo e gênero, todo sujeito possui elementos imaginativos femininos e masculinos. E, para ele, esses elementos estão diretamente ligados à constituição do sujeito e à criatividade.

Sales-Oliveira, Vilas-Boas e Las-Heras (2016) afirmam que o processo de socialização por meio da interpretação biológica de diferenças e com a influência do que é considerado feminino e masculino, reproduz desigualdades de caráter social, histórico e cultural. Apesar dos dados apontados, a tendência para naturalizar as diferenças de gênero ainda é fortemente disseminada tanto no senso comum, como até mesmo em algumas comunidades científicas (DASTON, 1992; PISCITELLI, 2009). É importante salientar que, como apontado por Ferreira (2018), os conhecimentos institucionalizados e legimitados pelas relações de gênero são saberes socialmente produzidos e reproduzidos.

Se pensarmos acerca da noção de gênero na infância, é compreensível a importância das relações sujeito-sujeito e sujeito-cultura no processo de construção dos papéis de gênero. Em seu trabalho, Vieira (2006) aponta que as crianças são tratadas de acordo com o sexo biológico desde a vida intrauterina e, muitas vezes essa forma de tratamento reproduz estereótipos de gênero. Para além do trabalho de Vieira (2006), outros autores também demonstraram que, desde muito cedo, as famílias iniciam a construção do gênero da criança (KROPENISCKI; PERURENA, 2017; LOPES; SILVA, 2018; SILVA, 2018). Entretanto, é importante ressaltar que a identidade de gênero não é algo somente imposto, mas sim: 
[...] uma espécie de (auto) construção, simultaneamente singular e colectiva, onde a participação num determinado género dá forma aos sentimentos e às cognições de cada indivíduo pelo facto de ser homem ou ser mulher (ORTIZ, 2010, p.17).

Sendo algo simultaneamente singular e coletivo, levanta-se o questionamento acerca das experiências no período da infância. Diante disso, Vasconcellos e Sarmento (2007), apontam que as experiências no período da infância são indissociáveis do contexto em que a criança está inserida. Nesse sentido, devem-se considerar fatores socioculturais como elementos que também são constituintes da subjetividade (RUA, 2007; COELHO, 2007).

Quando se fala em infância, dois principais pontos de associação são a escola e o brincar. Se relacionado à questão de gênero, autores como Silva e Lopes(2018), Ferp, Ferreira e Gouveia (2017), Lima (2019) e Suman (2018) indicam que brinquedos e brincadeiras têm um papel importante para a construção do gênero. Em seu livro "Brinquedos e companhia", Brougère (2004) aponta tal afirmação e complementa relacionando ao ambiente escolar, afirmando que as brincadeiras desempenham um papel importante, visto que:

[...] vemos em ação, ao mesmo tempo, a organização do desejo da criança, a influência dos pais, a pressão cultural tanto quanto a econômica. Aí a dicotomia masculino-feminino está mais ou menos institucionalizada. Também voltaremos a encontra-la, é verdade, nas brincadeiras "espontâneas" sem brinquedos, como as que podem ser observadas no pátio de recreio de uma escola de Ensino Fundamental (p.296-297).

Além disso, Coelho (2007) afirma que o processo de brincar também possibilita a identificação de padrões de comportamentos sociais que dão visibilidade ao mundo aos quais as crianças realmente pertencem. Isso se dá, em razão de ser no processo de ser criativo que ocorrem as trocas nas relações sociais, sendo por meio da brincadeira e do brincar que valores, pensamentos, ensinamentos e costumes do grupo cultural são transmitidos, e oportunizam formas de expressão das crianças que brincam (OLIVEIRA, SAWAIA, 2009).

Como afirma Gilles Brougère, em seu livro "Brinquedo e cultura" (BROUGÈRE, 2010), o brinquedo é algo que, para além de um simples objeto, é dotado de forte valor cultural. É um objeto complexo que permite que a criança compreenda o funcionamento da cultura sendo, antes de tudo, um fornecedor de representações manipuláveis e um suporte de alguma representação cultural. Nesse sentido, o autor afirma que 
"manipular brinquedos remete, entre outras coisas, a manipular significações culturais originadas numa determinada sociedade" (BROUGËRE, 2010, p.45). Assim, pode-se dizer que a brincadeira seria uma forma de entrada na cultura, um fator de assimilação dos elementos culturais, visto que a prática lúdica permite a apropriação de códigos culturais, e também apresenta importância crucial no processo de socialização. A criança situa assim, uma prática lúdica diante de imagens constituídas nos brinquedos, e ao mesmo tempo de imagens provenientes do seu círculo social (BROUGÈRES, 2010).

Em seu artigo "O brincar e a invenção do mundo em Walter Benjamin e Donald Winnicott”, Marie Claire Sekkel (2016) apresenta o brincar como atividade fundamental e que se encontra presente em todas as culturas, sendo a brincadeira fundante e permanente na vida cultural. Ela aponta a centralidade da brincadeira para o desenvolvimento humano e para a vida da e na cultura como um ponto de convergência. Além disso, afirma que Winnicott aborda o "movimento das crianças de trazer fragmentos da realidade cultural para a brincadeira, reinventando, a partir deles, um mundo próprio" (SEKKEL, 2016, p.90).

Em suas discussões, para além de dizer o que seria cultura, Winnicott (2019) propõe uma reflexão sobre a experiência cultural, experiência esta, tida como uma extensão da ideia dos fenômenos transicionais e da brincadeira. Continuando esse raciocínio, Winnicott (2019) complementa e afirma que as experiências culturais se iniciam por meio da criatividade que é manifestada na brincadeira. Ela começaria por jogos que conduzem ao campo da herança humana, incluindo as artes, mitos, religião, filosofia, entre outros (WINNICOTT, 2007). O autor (2007) informa que a transmissão de valores morais e questões relacionadas à civilização e a cultura, depende da provisão de exemplos para a criança, e tais exemplos podem ser observados por meio da expressividade do brincar infantil. A criatividade, a espontaneidade e o brincar podem ser enquadrados entre os pontos centrais da teoria de Winnicott. Por meio de sua posição afirmativa, o autor representa tais aspectos de maneira inovadora e original e os relaciona com o processo de subjetivação, a constituição do self e com a relação sujeito-sujeito e sujeito-ambiente.

É com base na criatividade que Winnicott (2019) discute sobre experiência cultural como possibilidade de criação e de recriar algo no espaço potencial. Esse espaço (WINNICOTT, 2019) se projeta e interpõe entre o indivíduo e o ambiente, possibilitando o encontro entre a realidade 
interna e a externa, seja em relação à materialidade do ambiente, ou a subjetividade dos indivíduos. Assim, a obra de Winnicott enfatiza a centralidade do meio ambiente e das relações do sujeito no processo de subjetivação.

Percebe-se assim que, conhecer a experiência de brincar e as brincadeiras das crianças, assim como as redes de sociabilidade que produzem e são perpassadas, se mostra academicamente relevante para o desenvolvimento de mais estudos e reflexões sobre infância e gênero. Em relação à relevância social, aponta-se a possibilidade de um espaço de transformação social por meio de experiências lúdicas, visto que, como afirmado por Winnicott (2019, p.87) "o brincar é, por si só, uma terapia". Também é refletida a importância de possibilitar um espaço lúdico para crianças em desenvolvimento e que vivem em uma zona caracterizada por dificuldades econômicas, estruturais e políticas.

Diante do exposto, o presente trabalho, inspirado em parte da dissertação sobre brincadeiras e cultura, visa analisar os estereótipos e as relações de gênero através de momentos lúdicos com crianças na préescola. Para isso, busca-se articular a análise dos dados com uma perspectiva psicossocial do desenvolvimento humano. Visto que, segundo o clínico e teórico Donald W. Winnicott (2007), a constituição subjetiva é indissociável do ambiente, assim, deve-se sempre levar em consideração o contexto relacional e social em que o indivíduo se insere e se desenvolve (ARAÚJO, 2007).

\section{Método}

\section{Tipo de estudo}

Como proposta metodológica, é apresentada uma pesquisa de caráter qualitativo, o que possibilita que pesquisadores utilizem uma variedade de práticas interpretativas que se interligam a fim de compreender melhor determinado assunto (TUZZO; BRAGA, 2016).

Para isso, propõe-se a pesquisa-ação, uma metodologia de caráter intervencionista (LINDGREN; HENFRIDSSON; SCHULTZE, 2004) e também participativo (TOLEDO; JACOBI, 2013) que possibilita um espaço de atividade psicossocial em grupo, como um modo específico de abordar crianças a fim de construir conhecimento com eles e para eles. Como discutido por Toledo e Jacobi (2013), esta metodologia é fundamentada na preocupação em garantir uma participação ativa do 
grupo, garantindo o envolvimento dos participantes no enfrentamento de problemas.

\section{Cenário metodológico}

Nesta pesquisa, foi realizada uma triangulação sistemática que, de acordo com Flick (2009), é um tipo de metodologia que ocorre a partir da combinação de perspectivas e métodos apropriados que possibilitem a percepção de aspectos distintos de um mesmo problema. Assim, a pesquisa qualitativa pode se apoiar em metodologias de investigação diversificadas, com a proposição da triangulação como olhares múltiplos que se complementam e que podem enriquecer a pesquisa como um todo. A multiplicidade de olhar nesta pesquisa ocorre ao unir pesquisa-ação por meio de oficinas lúdicas, a produção de diários de campo das pesquisadoras e a análise das produções infantis e momentos lúdicos.

Esta é uma proposta que visa uma participação ativa tanto de quem realiza a pesquisa, quanto da participação das crianças que constituem o grupo. Assim, considerando a fala infantil como um construto social que pressupõe discursos disponíveis na cultura (JOBIM E SOUZA; PEREIRA, 1998), a proposta desta pesquisa é a de possibilitar um espaço em que as crianças sejam escutadas e valorizadas em suas múltiplas vozes e considerações acerca dos temas abordados. Ouvir a criança é visibilizar sua experiência, oferecendo-lhe um lugar de protagonista ativa de sua história.

Busca-se então investigar a vida de um grupo específico, em que se aproximam pesquisadoras e participantes, em atividades em que ambos aprendem, conhecem e (se) transformam, considerando as diversidades e a intervenção de caráter analítico, assim como um posicionamento éticopolítico e epistemológico da pesquisa. Para propor essa metodologia, o caráter interventivo ocorreu por meio da oportunidade de um ambiente que possibilite a espontaneidade e a criatividade, considerando a ideia de fenômenos transicionais de Winnicott (2019).

\section{Instrumentos}

O método intervencionista se deu por meio da atividade psicossocial em grupo, realizada a partir de oficinas lúdicas, tendo as crianças participantes como protagonistas. Para registro das oficinas, foi proposto o uso de diários de campo como um instrumento auxiliar para 
representar dados de observação participante, uma observação ativa de investigação na recolha de dados (PAWLOWSKI, et al., 2016).

Serão aqui descritas cinco das oficinas semanais realizadas, pois apresentaram elementos considerados pertinentes para a análise das relações de gênero do grupo em questão. As oficinas selecionadas consistiram nas seguintes propostas: criação de vínculos; desenho; escolha dos brinquedos preferidos; construção de brinquedos; livre e momento de despedida.

\section{Local e Participantes}

Faz-se importante situar os fatores ambientais e socioculturais em que esta pesquisa foi realizada. A zona sul da cidade de Maceió é localizada na planície lagunar e é uma zona caracterizada pela média e baixa renda de seus moradores. O bairro selecionado é considerado um bairro periférico que surgiu, a partir de um arrabalde de pescadores às margens da Lagoa Mundaú. De acordo com Araújo (2018), a região lagunar da cidade de Maceió é um ambiente que se encontra em estado de degradação. Isso se dá pela ocupação irregular que a população desassistida realizou, assim como pela ausência de uma política ambiental e urbana eficiente. Para além disso, as desigualdades sociais e econômicas não atendidas pelas políticas públicas acabam por ocasionar maior vulnerabilidade social para os moradores.

Faz-se importante, então, considerar a desigualdade estrutural e histórica do Brasil, mas, principalmente do estado de Alagoas. De acordo com uma pesquisa realizada no ano de 2017 pelo Instituto Brasileiro de Geografia e Estatística (IBGE), 25,4\% da população do país se encontra em situação de pobreza. Dessa porcentagem, quase metade é constituída por nordestinos e, o estado de Alagoas apresenta o $3^{\circ}$ lugar no indicador de pior estado. $O$ conceito de pobreza aqui adotado, remete a privações de variados tipos e é entendido como um fenômeno multidimensional (MOURA JR; SARRIERA, 2019; XIMENES, et al., 2019; BARBOSA, 2020). O IBGE afirma ainda, que a pobreza atinge mais fortemente crianças e jovens entre o e 14 anos, sendo uma estatística de 42 a cada 100 crianças, afetadas principalmente pelo acesso precário à comunicação e serviços de saneamento básico.

Mas, apesar das dificuldades estruturais, econômicas e políticas, essa região possui grande riqueza histórica e culturais, demonstradas em atividades realizadas por grupos que promovem a valorização, 
preservação e divulgação da cultura popular alagoana. Esses grupos realizam danças, músicas e produções artísticas artesanais e, como dito por Nonato Lopes - Presidente da Associação de Folguedos - a comunidade quer ser identificada por suas criações e atividades culturais. De acordo com Nonato, eles querem "ser vistos de outra forma pela sociedade. Tem muita gente séria e de bem que mora na periferia" (CINARA, 2009).

Nesse bairro periférico da cidade de Maceió, foi escolhida uma creche escola de natureza filantrópica para realização da pesquisa. $\mathrm{O}$ grupo participante foi formado por 20 crianças, sendo 7 meninas e 13 meninos, todos com idades entre os 5 e 6 anos, e que constituem o último ano de estudos da Creche Escola.

\section{Análise dos Dados}

Para a análise dos dados, foram consideradas as produções das crianças, os momentos lúdicos e os diários de campo, estes produzidos com base nas observações das pesquisadoras. Todos os materiais produzidos nas oficinas foram registrados e salvos em um banco de dados próprio para a pesquisa, criado por meio do Drive no Gmail da pesquisadora principal.

Os elementos de análise foram submetidos à técnica de Análise de Conteúdo (BARDIN, 2016), que consiste em um conjunto de técnicas de investigação. Essas técnicas permitem que se descreva as informações de forma objetiva e sistemática, podendo ser analisadas qualitativamente.

Essa é uma técnica que consiste em três fases. Na primeira fase, conhecida como pré-análise, foi realizada uma leitura flutuante dos materiais coletados a fim de elaborar os indicadores da pesquisa. $\mathrm{Na}$ segunda fase, de exploração, foi elaborada a codificação e a categorização desses indicadores. Essa codificação ocorreu por meio da Unidade de Registro (UR) que diz respeito ao processo de seleção dos temas recorrentes nos materiais analisados, e por meio da Unidade de Contexto (UC), que se refere a frases e/ ou detalhes presentes nas produções, e é usado como base para compreender a unidade de registro (BARDIN, 2016). Essas etapas possibilitaram o desenvolvimento de categorias temáticas para análise e discussão do material. 
Por fim, foi realizada a última fase, momento em que é feito o tratamento dos resultados por meio da interpretação dos dados encontrados.

\section{Aspectos Éticos}

É importante ressaltar que, após a concordância da instituição, esse projeto foi encaminhado ao Comitê de Ética da Universidade Federal de Alagoas (UFAL) por meio da Plataforma Brasil, e obteve parecer favorável com CAAE número 16339119.9.0000.5013. Somente após esse parecer, foram iniciadas as oficinas com as crianças. Todas as crianças frequentaram regularmente às aulas no período de realização da pesquisa, aceitaram participar das oficinas por meio do Termo de Assentimento Livre e Esclarecido (TALE) e tiveram os Termos de Consentimento Livre e Esclarecidos (TCLEs) assinados pelos pais ou responsáveis. Vale salientar que, em respeito aos aspectos éticos no envolvimento de seres humanos (BRASIL, 2016), esta pesquisa visou pela proteção aos participantes e manteve, assim, o sigilo dos dados das crianças, pais, responsáveis e da creche escola. Foram utilizados, então, nomes fictícios a fim de censurar possíveis identificações, tornando público apenas o material coletado e analisado.

Visto Maceió ser uma cidade nordestina com forte raiz indígena, e seu nome ser uma modificação da palavra maça-y-ok, cuja etimologia em tupi significa "o que tapa o alagadiço" (SECOM MACEIÓ, 2013), fazendo um jogo também com a região lagunar selecionada, foram escolhidos nomes fictícios tupis para as crianças. Assim, os meninos são representados por: Ubiratã, Tupã, Iborê, Kaique, Cauê, Juraci, Raoni, Airy, Iraê, Moacir, Kadu, Peri e Jurandir. Já as meninas: Tainá, Yara, Iracema, Araci, Moema, Mayara e Tauane.

\section{Resultados}

Para melhor discutir os resultados, decidiu-se por, inicialmente, apresentar dados ocorridos e observados nas oficinas que tenham relação com o tema proposto. Após, são discutidas as categorias temáticas desenvolvidas a partir dos materiais analisados. 


\section{Oficina para Criação de Vínculos}

Tomando como ponto de partida que a creche escola em que foi realizada a pesquisa apresenta uma proposta que respeita e propõe atividades criativas e lúdicas no dia a dia das crianças, todas as oficinas foram planejadas com o intuito de estimular ainda mais as relações entre as crianças e os processos criativos e expressivos. As oficinas variaram entre momentos lúdicos livres e propostas inicialmente guiadas, mas sempre respeitando as livres formas de expressão das crianças participantes.

A primeira oficina teve como proposta principal a apresentação das crianças participantes e das pesquisadoras, a fim de dar início a criação de vínculos. Inicialmente, as crianças se apresentaram e comentaram sobre o que mais gostam de brincar e, diante das falas das crianças, foram observados alguns tipos de brincadeiras e brinquedos mais comuns, foram:

- Brincadeira mais comuns entre os meninos: Super-heróis, à exemplo do homem de ferro.

- Brincadeira mais comum entre as meninas: Brincadeiras relacionadas a casa, como brincar de cozinhar.

- Brinquedos mais comuns entre os meninos: bonecos, dinossauro, carros.

- Brinquedos mais comuns entre as meninas: bonecas, bichos de pelúcia.

- Brinquedos da creche mais comuns, utilizados em grupo: o trem, a casinha, a pesca, um trem de madeira, bola, dominó.

\section{Oficina de Desenho}

A proposta dessa oficina foi a realização de desenhos das famílias. Isso possibilitou que as crianças falassem um pouco mais sobre seus parentes e suas relações familiares. Durante o momento de produção, as crianças mantiveram conversas. Contaram sobre acontecimentos e brincadeiras na lagoa e sobre como foi a semana de cada um.

Sobre as questões de gênero, os pontos que chamaram atenção nesse dia dizem respeito a duas falas de Tainá e Peri. Enquanto as crianças realizavam suas produções, costumavam explicar o que estavam 
desenhando e quem eram os personagens das produções. Foi nesse momento que as seguintes falas ocorreram:

Tia, tô desenhando meu pai vestido de mulher. Às vezes ele se veste de mulher e às vezes de homem. Minha mãe não gosta quando ele se veste de mulher, mas usa as roupas de homem dele (Tainá, sic).

Oh tia, tô desenhando minha irmã com roupa de homem porque ela gosta de vestir roupa de homem (Peri, sic).

Nesse dia, Tainá também apresentou sentimentos de competitividade ao considerar os lados da sala como times e falar "os desenhos do meu time estão mais bonitos... mais coloridos" (Tainá, sic.).

\section{Oficina de escolha dos brinquedos preferidos}

Já na oficina seguinte que também teve como proposta ocasionar um momento lúdico, foi utilizado como base para seu planejamento a teoria de Winnicott, visto que questões relacionadas a brincadeiras e amizades são pontos relevantes para este teórico. Nesse sentido, a finalidade desse dia foi poder observar tais questões durante momentos de brincadeira.

Inicialmente, a ideia da oficina seria para que as crianças levassem seus brinquedos favoritos para a creche. No entanto, visto que algumas crianças haviam comentado em outros momentos sobre ter poucos brinquedos ou a necessidade de pegar brinquedos emprestados com os vizinhos, foi decidido que seria mais interessante pedir para que as crianças escolhessem brinquedos da própria creche, como uma tentativa de não causar incômodo ou mal estar em quem não tivesse condições de levar algum brinquedo.

Antes da escolha dos brinquedos, no momento de conversa com as crianças, constantemente Tainá realizava tentativas de sair do seu lugar e ficar no lugar de colegas que estavam mais próximos as pesquisadoras, numa tentativa de ter mais atenção para si. Isso resultou na criação de um apelido por parte de alguns colegas, que começaram a chamá-la de "Tainá cavala"(sic). Foram feitas intervenções para que o uso do apelido cessasse.

É importante ressaltar que, nesse dia, a organização do salão de recreação onde as oficinas foram realizadas, estava diferente. Foi observada a presença de uma sacola cheia de brinquedos, colocada pelos profissionais da creche, e que antes não faziam parte da coleção de brinquedos do salão. A curiosidade sobre a novidade dos brinquedos 
afetou a escolha de algumas crianças no momento de selecionar seus brinquedos favoritos, mas elas ficaram livres para escolher entre os brinquedos já existentes e os novos.

Como citado anteriormente, grande parte dos brinquedos escolhidos nesse dia também apresentaram distinções claras entre meninas e meninos. Enquanto a maioria das meninas se voltou para bonecas, bichos de pelúcia, casinha e cozinha, os garotos escolheram bonecos de super-heróis e monstros, animais mitológicos como dragões e dinossauros, dominó e armas.

No entanto, os tipos de escolhas não foram unânimes. Peri foi um garoto que se diferenciou pela escolha de uma casinha de brinquedo que possui escorrega e toca música. Moema foi uma garota que escolheu vários brinquedos de casinha e boneca mas, dentre eles, também tinha um quebra-cabeças. E apesar de não ter sido sua escolha inicial, Tainá decidiu brincar com o trem de madeira e se negou a compartilhá-lo com os colegas, talvez em reação ao apelido recebido.

Após as escolhas dos brinquedos, as crianças tiveram um momento de brincadeira com as pesquisadoras. Algumas se mostraram em dúvida entre brincar com os brinquedos escolhidos ou com outros presentes no salão. Para essa indecisão, apresentaram uma saída criativa e uniram os brinquedos escolhidos com o uso do ambiente, uma forma interessante de ocupar o espaço destinado a todos.

Exceto Moema que se isolou e não aceitou dividir seus brinquedos, as crianças se mostraram abertas para brincadeiras em grupo e foi possível observar afinidade entre eles. Como exemplo, é apontado o grupo de garotos que escolheram as armas. Raoni, Kaique, Airy e Juraci se uniram em suas brincadeiras e decidiram brincar de polícia e ladrão. $\mathrm{Ou}$ no caso de Kadu e Moacir que brincaram de luta com os bonecos escolhidos e Aracy, Tauane e Maynara que brincaram juntas com suas bonecas.

Foi possível observar maior afinidade para brincadeiras em grupo entre crianças do mesmo sexo. No entanto, essa afirmação não anula a possibilidade de brincadeiras em conjunto entre meninos e meninas.

\section{Oficina de construção de brinquedos}

Nesta oficina lúdica foi proposto às crianças que criassem brinquedos com materiais recicláveis. Esse foi mais um dia com a 
oportunidade de analisar questões que envolvem o brincar e as brincadeiras, amizade, cultura e criatividade.

Nesse dia foram disponibilizados, pelas pesquisadoras, materiais como, latas de leite, garrafas, barbantes, bolas de sopro, potes de sorvete, tampas de garrafa e de latas, palitos de picolé, potes e fita crepe.

Inicialmente as crianças pareciam mais contidas, brincando de forma mais simples apenas enchendo bolas de sopro. Mas, passados alguns minutos, o grupo se mostrou mais criativo e utilizaram a imaginação para criar seus brinquedos. Dentre as produções que mais chamaram a atenção, estão: um trem de bolas posteriormente transformado em polvo, helicópteros, balão, robôs, máquina de corações, enfeite para a casa, bolsa, pulseira e colar.

Figura 1: Polvo.

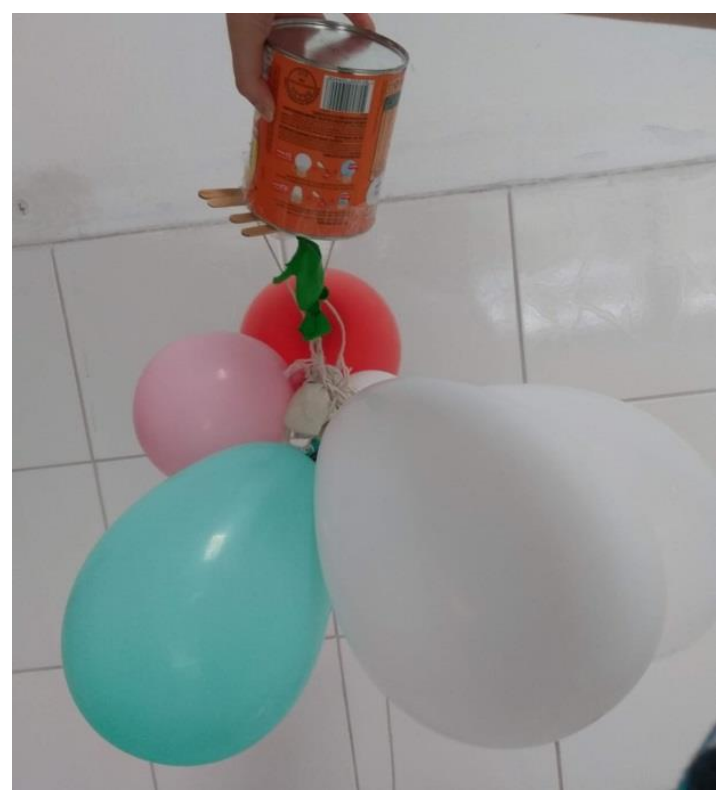

Fonte: Criação de Ubiratã, 5 anos. Fotografia da autora/2019. 
Alana Madeiro de Melo BARBOZA, Paula Orchiucci MIURA, Adélia Augusta Souto de OLIVEIRA, Heliane de

Figura 2: Helicóptero

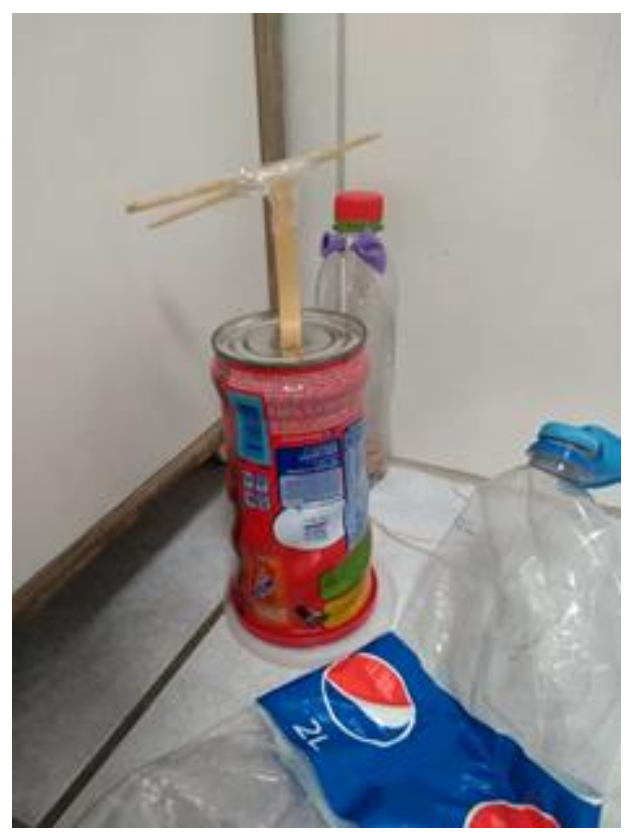

Fonte: Criação de Juraci, 6 anos. Fotografia da autora/2019.

Figura 3: Robô de lata.

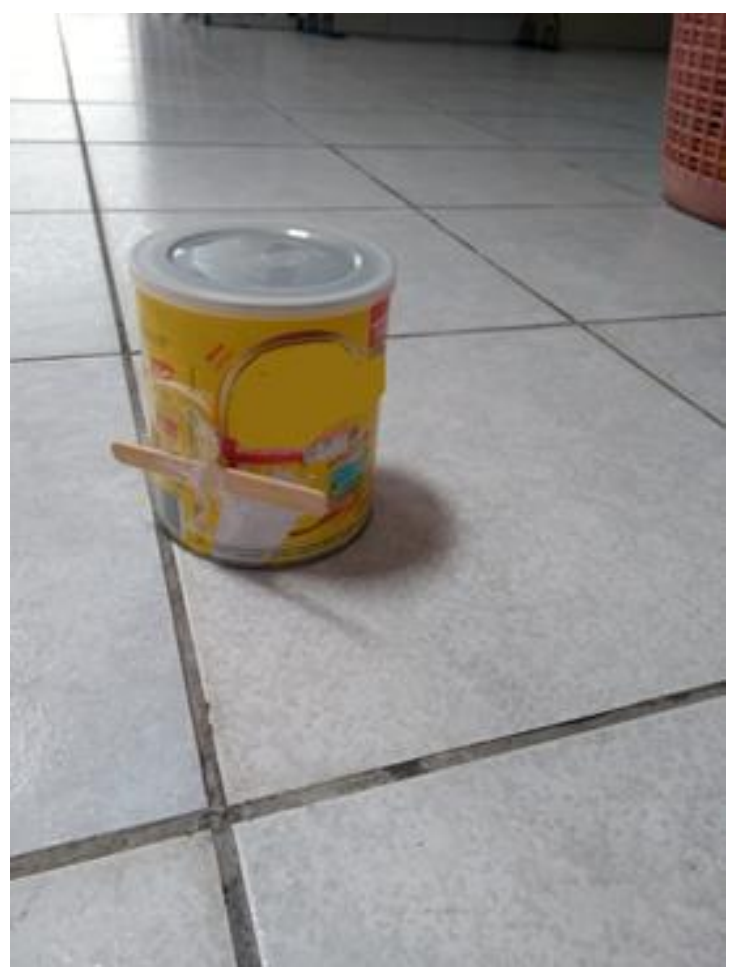

Fonte: Criação de Kaique, 6 anos. Fotografia da autora/2019. 


\section{Figura 4: Robô de plástico}

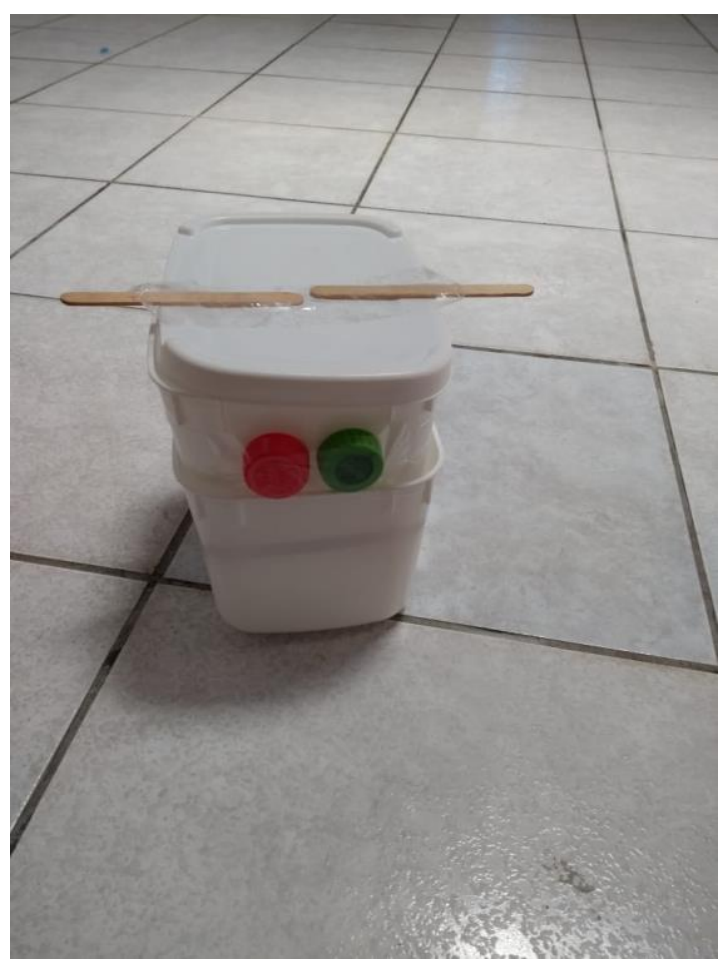

Fonte: Criação de Moema, 6 anos. Fotografia da autora/2019.

Figura 5: Balão

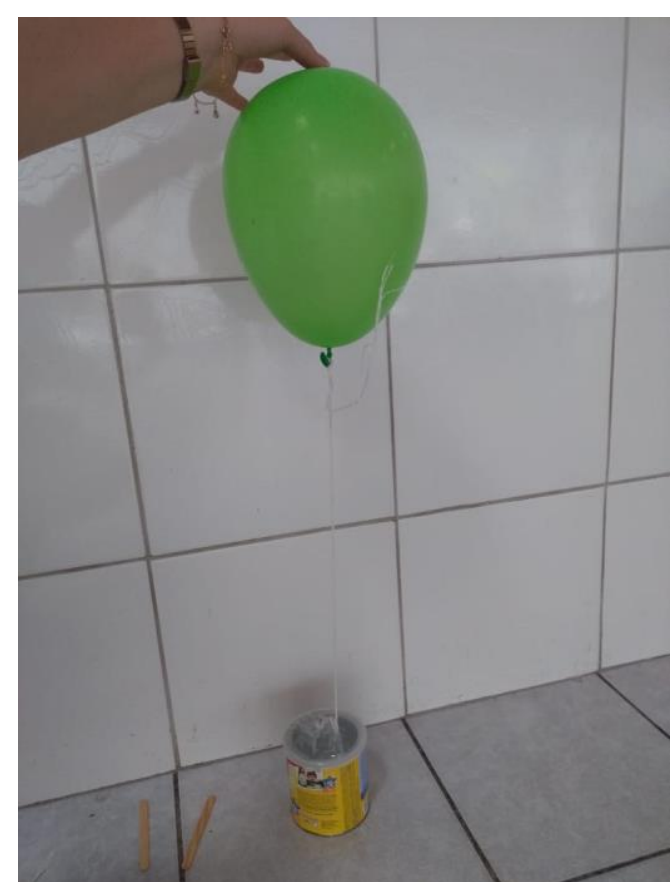

Fonte: Criação de Raoni, 5 anos. Fotografia da autora/2019. 
Alana Madeiro de Melo BARBOZA, Paula Orchiucci MIURA, Adélia Augusta Souto de OLIVEIRA, Heliane de

Almeida Lins LEITÃ̃O

Figura 6: Máquina de corações

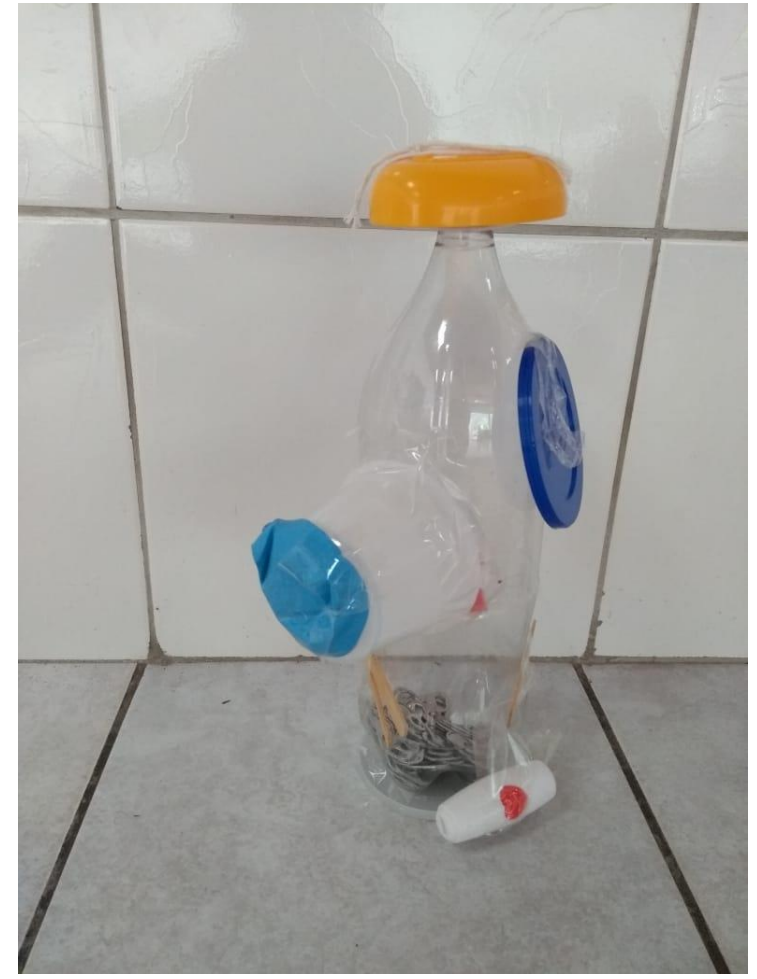

Fonte: Criação de Yara, 5 anos. Fotografia da autora/2019.

Figura 7: Enfeite de casa

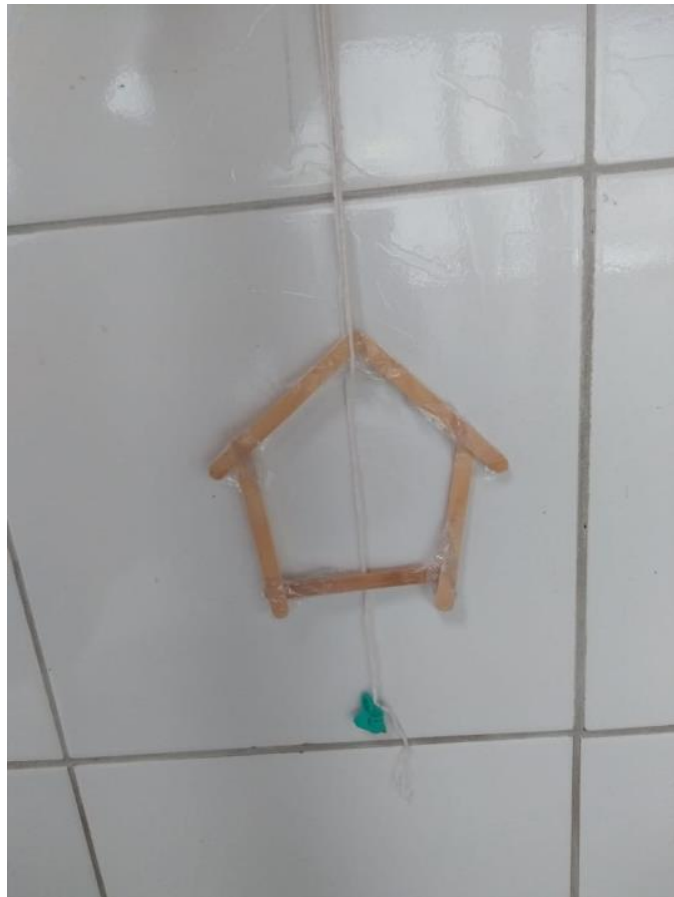

Fonte: Criação de Peri, 5 anos. Fotografia da autora/2019. 
Figure 8: Bolsa

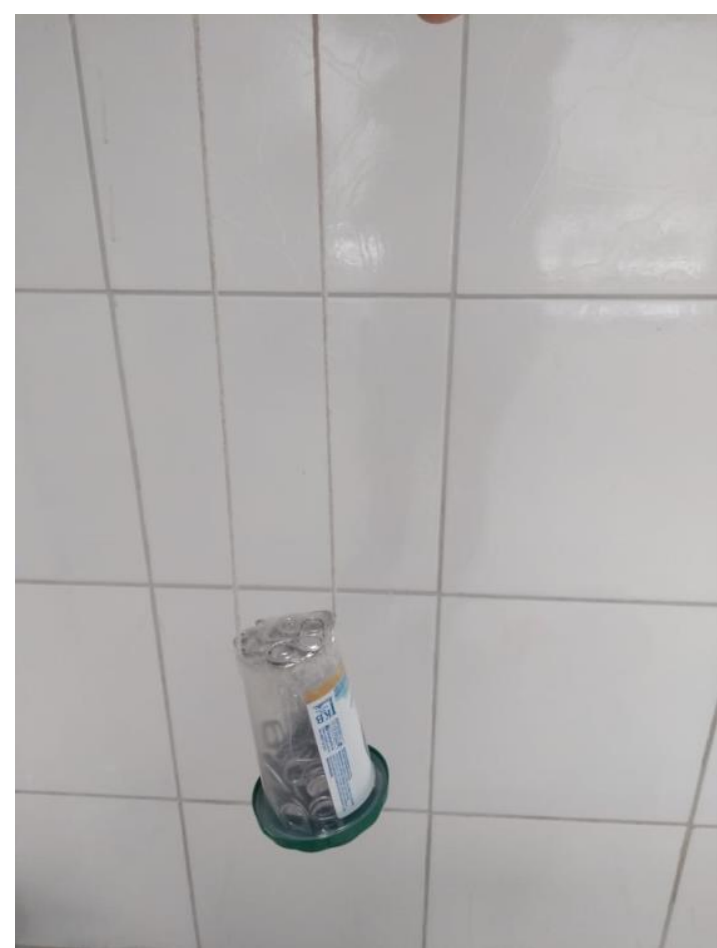

Fonte: Criação de Iracema, 5 anos. Fotografia da autora/2019.

Figure 9: Colar

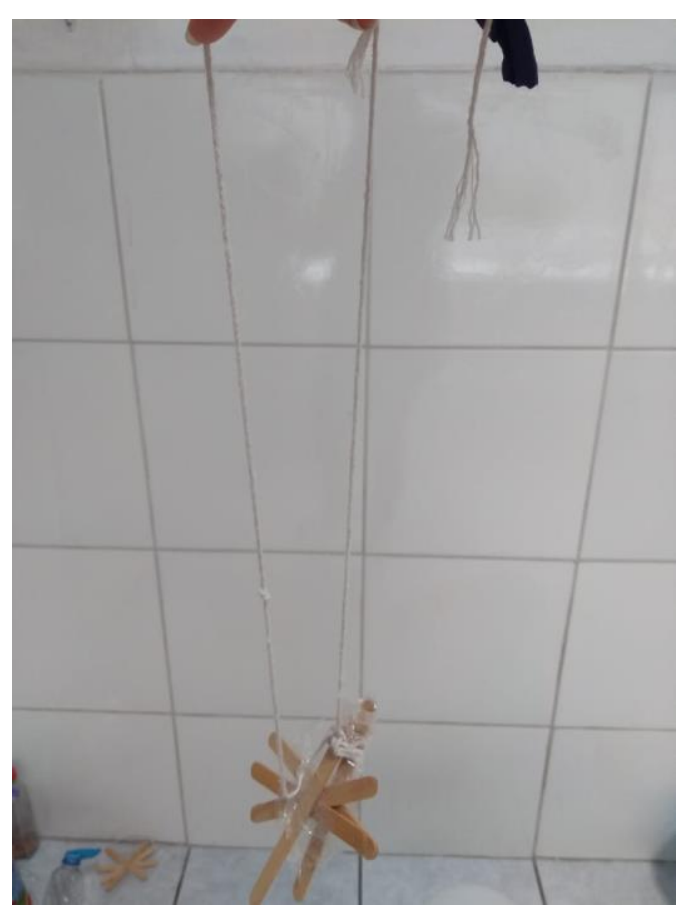

Fonte: Criação de Araci, 5 anos. Fotografia da autora/2019. 


\section{Oficina livre e momento de despedida}

Nesse dia, todos brincaram em conjunto e de diferentes brincadeiras - como bola, pega-pega, dominó, polícia e ladrão e o trem -, apesar de que, em alguns momentos, os garotos brincaram mais de futebol, trem e pega-pega entre si, enquanto as garotas focaram mais em brincadeiras de casinha. Chama-se atenção para a brincadeira mais constante que foi polícia e ladrão. Os garotos brincavam de polícia e ladrão e, ao mesmo tempo, participavam de outras brincadeiras, invadindo a casinha, roubando a bola, etc. Alguns garotos fizeram o papel dos policiais, utilizando armas de brinquedos. Eles gritavam enquanto prendiam as outras pessoas que faziam parte da brincadeira. Percebe-se que temas relacionados à polícia apareceram de forma constante e agressiva nas brincadeiras entre meninos.

\section{Análise e discussão}

Neste tópico estão detalhadas e discutidas as categorias temáticas de análise dos resultados. Para isso, foram elaboradas quatro categorias, são elas: "bela, recatada e do lar?"; "o direito da expressão da agressividade é somente dos meninos?"; "contradições às imposições de gênero"; e "a dimensão social do brinquedo".

\section{Bela, recatada e do lar?}

Apesar da temática de gênero surgir a partir de práticas e manifestos como uma forma de mulheres reivindicarem o reconhecimento da igualdade de direitos e da individualidade, culturalmente, ainda são perpassadas atitudes e frases que produzem "verdades" sobre a legitimação da inferioridade feminina (PERUZZO, 2016).

É importante ressaltar, no entanto, que se responsabilizar por cuidados e pela casa não quer dizer, necessariamente, ser inferior a alguém. O ponto central de discussão aqui é apontar como, muitas vezes, a cultura impõe regras limitadoras nas escolhas de vida das mulheres.

Culturalmente, por mais que a figura feminina esteja ganhando cada vez mais espaço no mercado de trabalho, na política e na pesquisa, por exemplo, ainda são impostos os mais variados atributos à mulher. Mesmo que ela trabalhe fora de casa, constantemente ainda é cobrado da 
figura feminina o papel de ser mãe, esposa, dócil, sentimental, vaidosa e responsável pelo trabalho doméstico.

Se relacionarmos esses pontos aos momentos de brincadeiras nas oficinas, podemos observar que, em algum momento dos encontros, todas as garotas reproduziram tais questões. Muitas das brincadeiras, falas e produções giraram em torno de um ideal de beleza, como na produção de colares, pulseiras e bolsas, ou no discurso de um ideal corporal feminino no qual o feminino considerado bonito é uma garota ou mulher branca e magra. A constante tentativa de alcançar esse padrão ideal corporal desde a infância, proporciona inquietações e questionamentos acerca da objetificação do corpo feminino. Como apontado por Costa (2018), a objetificação do corpo feminino está presente em nossa cultura de forma enraizada nos meios midiáticos e sociais e isso faz com que esse corpo se torne um objeto de desejo e consumo, banalizando e até desconsiderando por completo o potencial intelectual das mulheres. É preciso questionar tais imposições e quais as consequências disso para a saúde de meninas e mulheres.

Como afirmado por Sousa e Sirelli (2018), a vigilância e cobrança pela imagem corporal considerada perfeita começa desde a infância. Como afirmado pelas autoras, essa cobrança é:

[...] um importante fato para o aprisionamento objetivo e subjetivo das mulheres, uma das formas de repressão e opressão mais difíceis de identificação e libertação. A padronização da beleza, que acarreta uma série de problemas de proporções físicas e psicológicas, em que a mulher se vê na obrigação de estar enquadrada a determinado tipo de corpo, de cabelo, em que até mesmo algo inevitável e comum a todos como o envelhecer lhes é negado (SOUSA; SIRELLI, 2018, p.329).

Diante de tais apontamentos, se faz importante citar que, como dito por Foucault (1978), para além de ser um texto da cultura, o corpo principalmente o feminino - é um lugar prático de controle social. Esse raciocínio pode ser complementado pela defesa da antropóloga Mary Douglas (1982) sobre o corpo também ser uma forma simbólica visto que - assim como acontece com o brinquedo e as brincadeiras - a cultura inscreve regras e reforços sobre o corpo feminino.

Em todas as oficinas também foram observados momentos voltados para situações domésticas, com brincadeiras mais relacionadas a cozinha e cuidados com bonecas. De acordo com Winnicott (1990), visto que a brincadeira tem influência direta da cultura, a menina acaba por 
brincar de uma forma em que é considerada verdadeiramente feminina, demonstrando uma tendência - cultural - à maternidade.

Segundo Kishimoto e Ono (2008), isso se dá pois os padrões acerca do que seria feminino e masculino se estendem para a escolha de brinquedos e brincadeiras. Nesse sentido, diante da cultura em que estão inseridas, as meninas são ensinadas a valorizar a imagem corporal, a beleza e situações voltadas para atividades domésticas e papéis maternos (KISHIMOTO; ONO, 2008).

\section{O direito da expressão da agressividade é somente dos meninos?}

Percebe-se que a competição, a rivalidade e a raiva são elementos que podem aparecer durante as brincadeiras e isso gera uma reflexão acerca da agressividade. É importante ressaltar, no entanto, que existe diferença entre agressão e agressividade. De acordo com Winnicott (2005), o ato agressivo tem relação com o processo de distinção entre o eu e o que e o não-eu, no entanto, sendo papel do ambiente conter tais atos e ajudar na resolução de conflitos.

Sobre a agressividade, Winnicott buscou elucidar que as raízes da agressão são inerentes a natureza humana e afirma que "por um lado, constitui, direta ou indiretamente, uma reação à frustração. Por outro lado, é uma das muitas fontes de energia de um indivíduo" (WINNICOTT, 2005, p.102). Se relacionado a momentos de brincadeira, Winnicott (2019) complementa que, por meio do brincar, a criança consegue externalizar sentimentos como ódio, raiva, ressentimentos e cóleras recalcadas, além de conseguir elaborar e lidar com angústias. No entanto, socialmente existem imposições sobre quem tem direito a se expressar de forma mais ou menos agressiva.

Durante as oficinas, foi observado que a expressão da agressividade parece ser uma liberdade exclusiva dos garotos. Enquanto meninos apresentaram constantemente brincadeiras que se associam à questão da expressão da agressividade, como luta, polícia e ladrão, armas e tiros, chutam e jogam a bola com força, nos momentos em que alguma garota reage de forma a expressar sua agressividade - seja numa reação a não compartilhar objetos, ou na tentativa de reivindicar mais atenção recebe retaliações em forma de apelido, como ocorreu com Tainá. 
Dentre as garotas do grupo, Tainá pode ser considerada a menina que mais se permitia expressar sua agressividade, seja na negação em dividir um brinquedo que consiste na montagem de um trem ou em momentos em que tentava ficar no lugar dos colegas mais próximos, numa disputa para conseguir se aproximar das pesquisadoras. No entanto, as reações de Tainá geraram algumas inquietações no grupo e algumas crianças passaram a chamá-la de "Tainá cavala" (sic). Foram realizadas as devidas intervenções para que o uso do apelido cessasse, mas ficou a reflexão sobre o por quê de apenas Tainá ter recebido apelido se durante todas as oficinas, os garotos reagiam de forma parecida durante os momentos de polícia e ladrão e de lutas, mesmo que em alguns momentos as pesquisadoras precisassem interferir para não se machucarem. Em sua dissertação, Pita (2010) também observou que brincadeiras com armas estão mais associadas a escolhas de garotos e à expressão da agressividade por meio do brincar.

Diante de tal reflexão, apontam-se algumas afirmações de Whitaker (1988). Segundo a autora, existem alguns atributos que são socialmente aceitos como sendo de meninos ou de meninas. No caso dos meninos, a agressividade é uma característica considerada socialmente importante em detrimento da sensibilidade, que deve ser reprimida. Já no caso das meninas, ocorre o contrário. Socialmente, a sensibilidade feminina é uma característica que deve ser estimulada e a agressividade não deve fazer parte do universo feminino (WHITAKER, 1988).

Assim, fica claro que, apesar da agressividade ser inerente ao ser humano independente de gênero e sexo, a expressão espontânea da agressividade é um atributo socialmente aceito apenas para meninos, e isso acaba por refletir nas escolhas de brincadeiras que necessitem de um comportamento mais ativo (WHITAKER, 1988).

No entanto, é importante refletir sobre as possíveis implicações da negação da agressividade para o desenvolvimento, visto que Winnicott (2005) afirma que a agressividade primária é base para a criatividade. Para este autor, é de suma importância o acolhimento e a compreensão da agressividade, pois é o que dá origem ao gesto espontâneo e criativo, importantes para as experiências de constituição do sujeito. Nos casos em que não ocorre o acolhimento, o movimento criativo do sujeito pode sofrer uma ruptura e impossibilita que o self se expresse verdadeiramente (WINNICOTT, 2005). 


\section{Contradições às imposições de gênero}

É importante reafirmar que as manifestações de interesse em determinados estilos de brinquedos e brincadeiras, muitas vezes se dão de forma naturalizada, mas não é algo natural. Sobre o fato de os modelos do que seria masculino ou feminino não serem naturais, Souza (2016) afirma que esses modelos estão mais relacionados a questões históricas e sociais, do que a questões biológicas.

Molinier e Welzer-Lang (2009) também apontam para a existência da masculinidade e da feminilidade como algo que se define na relação, com características e qualidades atribuídas de forma social e cultural. Os autores complementam tal pensamento afirmando que "são as relações sociais de sexo, marcadas pela dominação masculina, que determinam o que é considerado 'normal' - e em geral interpretado como 'natural' - para mulheres e homens" (MOLINIER; WELZER-LANG, 2009, p.101).

Por essas diferenças serem construídas de forma social e cultural e sendo a criança um ser ainda em formação, com seus primeiros contatos com objetos culturais e regras sociais, refletimos sobre a possibilidade de oposição às imposições de gênero.

Apesar de os brinquedos e brincadeiras serem utilizados com o intuito de classificar e rotular o gênero das crianças, na brincadeira, a criança pode transformar as representações, desenvolver novas significações para o brinquedo por meio do brincar e, consequentemente personalizar a realidade. Nesse sentido, Brougère (2010) afirma que "a brincadeira é, antes de tudo, uma confrontação com a cultura” (p.82), isso se torna um processo dinâmico de inserção cultural mas, ao mesmo tempo, em que a criança lida com conteúdos preexistentes, o brincar possibilita uma apropriação ativa. Sobre isso, Finco (2005) afirma que:

Os meninos e meninas brincam de tudo aquilo que lhes dê prazer: de bola, de boneca, de empinar pipa, de carrinho. Ao brincar com todos os brinquedos que desejam não deixam que ideias, costumes e hábitos, que já faziam parte da educação de meninos e meninas na primeira metade do século XIX, limitem suas formas de conhecer e vivenciar o mundo, determinando o que devem ser o que devem pensar e que espaços devem ocupar. Os brinquedos e brincadeiras são rotulados e classificados em determinado gênero, apresentando para as crianças uma hierarquização e uma cultura excludente (FINCO, 2005, p. 13). 
Apesar da maior parte das escolhas das crianças condizerem com as imposições de gênero, existiram momentos em que tanto meninos quanto meninas brincaram com bolas, casinhas, dominós e carros - como o trem -. Além disso, algumas falas questionam tais imposições, como as falas de Tainá e Peri acerca do gênero nas roupas de suas famílias.

Em outras ocasiões, Peri foi de encontro a imposições de gênero, quando escolheu brincar de casinha e criou um enfeite de palitos de picolé para pendurar em sua casa.

Apesar das escolhas mais voltadas para meninas com cuidados e afazeres domésticos e meninos com atividades mais agitadas e agressivas, fica perceptível que as conclusões acerca do que seria feminino ou masculino para as crianças mais novas ainda é algo em processo de construção. $\mathrm{O}$ que reafirma que tanto as questões de gênero, quanto os preconceitos atrelados a tais questões são construções culturais, históricas e sociais.

É importante ressaltar que a possibilidade de oposição às imposições, pode ser considerada um ato positivo e com relação direta a criatividade. Para Winnicott (2019), o ato criativo possibilita a continuidade de ser e a expressividade do verdadeiro self. Se opor a algo significa não ser passivo frente a situações que inibem a expressão criativa do verdadeiro self.

\section{A dimensão social do brinquedo}

Faz-se importante também discutir sobre a dimensão social do brinquedo. No decorrer das oficinas as representações sociais ocorreram por meio da demonstração de vivências que são perpassadas pela sociedade em que as crianças estão inseridas. Como exemplo, aponta-se a constante presença de trens - visto que o trem da cidade atravessa a zona -, a criação do polvo, relacionado a animais aquáticos e a presença da lagoa, e de elementos comumente femininos como pulseira, bolsa e colar.

Também é observada a forma como socialmente, as meninas são estimuladas a ter escolhas voltadas para afazeres domésticos e cuidados socialmente considerados maternos, e para os garotos, a escolha por futebol - visto ser um esporte altamente estimulado para meninos no Brasil -, polícia e ladrão - se levar em consideração que a constituição da polícia é majoritariamente masculina, e o bairro em questão sofrer 
represálias por ser reconhecido como um ambiente periférico, politicamente desassistido, em estado de degradação e vulnerabilidade.

Fica claro que, assim como dito por Brougères (2010), o brinquedo tem um peso social que abre possibilidades de ações que são coerentes com a representação social, não sendo uma representação fiel do mundo real, mas possui o peso de uma imagem cultural particularmente destinada a determinado objeto tido como brinquedo. Sobre isso, Brougères (2010) exemplifica afirmando que "não existe no brinquedo uma função de maternagem; há uma representação que convida a essa atividade num fundo de significação (bebê) dada ao objeto num meio social de referência" (p.16). O que ocorre, então, são associações de tradição cultural sobre representações do que seria do masculino e do feminino.

Como afirmado por Meira (2003), os brinquedos são objetos que evocam formações do social e revelam "traços da cultura em que se inscreve "(p.75). É algo que está imposto no dia a dia das crianças, seja nas relações familiares, escolares ou em relações sociais mais amplas. Sobre isso, Brougères (2010), afirma:

Quando a criança cresce [...] o mais provável é que ela vá procurar imagens sedutoras de seu futuro estado adulto, através da beleza, da riqueza ou da aventura. A diferença sexual é, aqui, essencial na valorização das imagens. O universo feminino parece ficar junto da família e do cotidiano, enquanto o do menino, que começa, sem dúvida, com a miniatura do automóvel, traduz a vocação para a descoberta dos espaços longínquos, escapando do peso cotidiano (p.20-21).

\section{Conclusão}

Foi observado que o funcionamento da cultura em que as crianças estão inseridas influencia diretamente na forma como a sociedade funciona e isso reflete nos entendimentos sobre gênero, o que influencia o brincar, as brincadeiras e os brinquedos, assim como ambientes cujo enfoque é o público infantil. Nesse sentido, a atribuição de papéis de gênero se enquadra como um fenômeno histórico que tem como intermédio a cultura a qual os sujeitos pertencem.

As brincadeiras são influenciadas por componentes culturais e sociais que impõem a estereotipia de gênero. Os brinquedos e ato de brincar que fazem uso dos papéis de gênero são estruturados a partir de significados culturais que são específicos da sociedade em que as crianças 
estão inseridas e pressupõem um repertório do que é ofertado como possibilidade para as crianças.

Porém, mesmo com a existência de sistemas sociais de segregação entre brincadeiras femininas e masculinas, considera-se que as crianças desenvolvem sentidos próprios às suas experiências. Assim, apesar da pré-existência de significados impostos nas relações de gênero, o processo criativo da brincadeira possibilita a potencialidade de superação dessas desigualdades.

A proposta dessa pesquisa foi possibilitar um espaço de expressão e comunicação, levando em conta as experiências e considerações das crianças acerca do tema proposto. Compreende-se que esse estudo alcançou um grupo pequeno selecionado na comunidade. No entanto, aponta-se a relevância e eficácia das oficinas realizadas como uma forma de possibilitar um espaço lúdico onde as crianças possam se expressar de forma livre e criativa, apesar de imposições sociais, como forma de ressignificar e até mesmo criar novas realidades no ambiente em que estão inseridas, apesar de algumas situações socialmente impostas pela realidade em que vivem.

\section{Referências}

ARAÚJO, Andrea Geórgia Souza de. A dinâmica da ocupação na favela sururu de capote: segregação socioespacial e exclusão social. 2018. 193 f. Dissertação (Mestrado) - Curso de Geografia, Instituto de Geografia, Universidade Federal de Alagoas, Maceió, 2018.

ARAÚJO, Conceição A. Serralha de. Uma abordagem teórica e clínica do ambiente a partir de Winnicott. 2007. 204 f. Dissertação (Mestrado) Mestrado em Psicologia Clínica, Núcleo de Práticas Clínicas, Pontifícia Universidade Católica de São Paulo, São Paulo, 2007.

BARBOSA, Vilkiane Natercia Malherme. As implicações psicossociais da pobreza na relação entre sentido de comunidade e desigualdades sociais de gênero no Parque da Liberdade. 2020. 170 f. Dissertação (Mestrado) Curso de Programa de Pós-graduação em Psicologia, Universidade Federal do Ceará, Fortaleza, 2020.

BARDIN, Laurence. Análise de conteúdo. Lisboa: Edições 70, 2016. 
BRASIL. Resolução CNS $n^{o}$ 51o, de o7 de abril. Ministério da Saúde. Conselho Nacional de Saúde. Brasília, 2016.

BROUGÈRE, Gilles. Brinquedos e companhia. São Paulo: Cortez, 2004.

Brinquedo e cultura. 8. ed. São Paulo: Cortez, 2010. (Coleção Questões da Nossa Época, 20).

CINARA, Gilca. Festival Olhar Circular revela diversidade de Alagoas. Portal de Noticiais. 5 jun. 2009. Disponível em: https://www.cadaminuto.com.br/noticia/12171/2016/12/21/delmirogouveia-jovem-e-baleado-apos-reagir-a-assalto-no-centro-da-cidade Acesso em: 3 jul. 2019.

COELHO, Mateus Gustavo. Gêneros desviantes: o conceito de gênero em Judith Butler 2018. 101f. Dissertação (mestrado) - Universidade Federal de Santa Catarina, Centro de Filosofia e Ciências Humanas, Programa de Pós-Graduação em Filosofia, Florianópolis, 2018. Disponível em: < https://repositorio.ufsc.br/handle/123456789/191493>. Acesso em: 27 jun. 2020.

COELHO, Glaucineide N. Brincadeiras na favela: a constituição da infância nas interações com o ambiente. In: VASCONCELLOS, Vera M. R.; SARMENTO, Manuel J. (Orgs.). Infância (in)visível. Araraquara: Junqueira\&Marin, 2007. p. 173-204.

COSTA, Ana Kerlly Souza da. Hipersexualização frente ao Empoderamento: a objetificação do corpo feminino evidenciada. In: SEMINÁRIO CORPO, GÊNERO E SEXUALIDADE, 7, 2018, Rio Grande. Anais VII Seminário Corpo, Gênero e Sexualidade. Rio Grande: Furg, $2018 . \quad$ p. 1-8. Disponível em: https://7seminario.furg.br/images/arquivo/338.pdf. Acesso em: 26 jun. 2020.

DASTON, Lorraine. The naturalized female intellect. Science in context, n.5, v.2. p.209-235. 1992.

DOUGLAS, Mary. Natural Symbols. New York: Pantheon. 1982.

FERP, Ugb; FERREIRA, Fauve Huback; GOUVEIA, Sonia de Alcantara. GENERO E BRINQUEDO: Como a boneca mais famosa do mundo influencia a construção de padrões e estereótipos. Episteme 
Transversalis, [S.l.], v. 7, n. 2, nov. 2017. Disponível em: <http://revista.ugb.edu.br/ojs302/index.php/episteme/article/view/63 2>. Acesso em 26 jun. 2020.

FERREIRA, Daniele da Silva. Construção da identidade de gênero: reflexões em contexto escolar. Psicologia.pt [S.1], v.7, n.1, p.62, mai 2018. Disponível em: <https://www.psicologia.pt/artigos/textos/TL0439.pdf> Acesso em: 27 jun. 2020.

FINCO, Daniela. Educação Infantil, Gênero e Brincadeiras: das naturalidades às transgressões. São Paulo: Unicamp, 2005.

FLICK, U. Introdução à pesquisa qualitativa. 3. ed. Porto Alegre: Artmed. 2009.

FOUCAULT, Michel. The History of Sexuality, Vol. I. New York: Pantheon, 1978.

. Herculine Barbin: O diário de uma hermafrodita. Rio de Janeiro: F. Alves, 1982.

IBGE - Instituto Brasileiro de Geografia e Estatística. Síntese de indicadores sociais: uma análise das condições de vida da população brasileira. Coordenação de População e Indicadores Sociais. - Rio de Janeiro: IBGE. 147p. 2017.

JOBIM E SOUZA, Solange; PEREIRA, Rita. Marisa. Ribes. Infância, conhecimento e contemporaneidade. In: KRAMER, Sonia \& LEITE, Maria Isabel (Orgs.). Infância e Produção Cultural. Campinas: Papirus. p. 2542. 1998.

KISHIMOTO, Tizuko Morchida; ONO, Andréia Tiemi. Brinquedo, gênero e educação na brinquedoteca. Pro-Posições, Campinas, v. 19, n. 3, p. 209223 Dec. 2008. em:

<http://www.scielo.br/scielo.php?script=sci arttext\&pid=S010373072008000300011\&lng=en\&nrm=iso > Acesso em: 26 jun. 2020.

KROPENISCKI, Fernanda Battagli; PERURENA, Fátima Cristina Vieira. RELAÇÕES DE GÊNERO EM CATÁLOGOS DE BRINQUEDOS: (CONTRA)INDICAÇÕES PARA O BRINCAR. Educ. Soc., Campinas, v. 38, n. 141, p. 965-981, Dec. $2017 . \quad$ Disponível em: 
<http://www.scielo.br/scielo.php?script=sci_arttext\&pid=So10173302017000400965\&lng=en\&nrm=iso > . Acesso em: 27 jun. 2020.

LIMA, Aline Dias dos Santos. Gênero e brincadeira em cena na escola. 2020. 63 f. Trabalho de Conclusão de Curso (Licenciatura em Pedagogia) - Unidade Delmiro Gouveia-Campus do Sertão, Universidade Federal de Alagoas, Delmiro Gouveia, 2019

LINDGREN, Rikard; HENFRIDSSON, Ola; SCHULTZE, Ulrike. Design Principles for Competence Management Systems:: a synthesis of an action research study.. MIS Quarterly, Minessota, v. 28, n. 3, p. 435-472, set. 2004 .

LOPES, Fernando José; SILVA, Crislane Santos. RELAÇÕES DE GÊNERO NA EDUCAÇÃO INFANTIL BRINCADEIRAS DE MENINAS E MENINOS. Revista de Pós-graduação Multidisciplinar, [S.l.], v. 1, n. 4, p. 167-174, aug. 2018. Disponível em: <http://www.fics.edu.br/index.php/rpgm/article/view/780>. Acesso em: 24 jun. 2020.

MEIRA, Ana Marta. Benjamin, os brinquedos e a infância contemporânea. Psicol. Soc., Porto Alegre , v. 15, n. 2, p. 74-87, Dec. 2003. Disponível em: $\quad$ http://www.scielo.br/scielo.php?script=sci arttext\&pid=S010271822003000200006\&lng=en\&nrm=iso Acesso em: 22 jun. 2020.

MOLINIER, Pascale; WELZER-LANG, Daniel. Feminilidade, masculinidade, virilidade. In: HIRATA, H. (Org.). Dicionário crítico do feminismo. São Paulo: Editora Unesp, 2009. p. 101-102.

MOURA JR., James Ferreira; SARRIERA, Jorge Castellá. Impactos das Diferentes Formas de Mensuração da Pobreza nas Variações do Índice de Bem-Estar Pessoal. Psic.: Teor. e Pesq., Brasília , v. 35, , 2019.

OLIVEIRA, Adélia A. S.; SAWAIA, Bader B. A infância experienciada em comunidades litorâneas. In.: LEITÃO, Heliane de A. L.; OLIVEIRA, Adélia A. S. (orgs.)Infância e juventude na comtemporaneidade: ouvindo os protagonistas. Maceió: Edufal, 2009. p.51-80.

ORTIZ, Paula (coord). Palmo e meio de igualdade. S.l.: Esdime - Agência para o Desenvolvimento Local no Alentejo Sudoeste. 2010. Disponível em https://www.esdime.pt/download/ged-3-

o02\%20palmo e meio de igualdade.pdf Acesso em: 20 jun. 2020. 
PAWLOWSKI, Charlotte Skau et al. Children's physical activity behavior during school recess: A pilot study using GPS, accelerometer, participant observation, and go-along interview. Plos One, Madrid, v. 11, n. 2, p. 1-12, 9 fev. 2016

PERUZZO, Nara Aparecida . Sofia: Bela, Recatada e do Lar. Implicações pedagógicas à mulher a partir do Livro $\mathrm{V}$ do Émile de Rousseau. In: 11 Reunião Científica Regional da Associação Nacional de Pesquisa e PósGraduação - ANPEd SUL, 2016, Curitiba - PR. 11 Reunião Científica Regional da Associação Nacional de Pesquisa e Pós-Graduação - ANPEd SUL, 2016. p.1-17.

PISCITELLI, Adriana. Gênero: a história de um conceito. In: ALMEIDA, Heloisa Buarque de; SZWALKO, José Eduardo(orgs.). Diferenças, igualdade. São Paulo: Berlendis \& Vertecchia. 2009. (Coleção sociedade em foco: introdução às ciências sociais).

PITA, Ana Regina da Silva. A interação do brincar em um espaço escolar entre crianças de 6 a 10 anos de idade: um estudo a partir da abordagem de Donald W. Winnicott. 2010. 124 f. Dissertação (Mestrado) - PósGraduação em Psicologia, Pontifícia Universidade Católica de São Paulo, São Paulo, 2010.

RUA, Maria A. Infância em territórios de pobreza: os falares e sentires das crianças. In: VASCONCELLOS, Vera M. R.; SARMENTO, Manuel J. (Orgs.). Infância (in)visível. Araraquara: Junqueira\&Marin, 2007. p. 205-244.

SALES-OLIVEIRA, Catarina, VILAS-BOAS, Susana; LAS-HERAS, Soledad. Estereótipos de género e sexismo em docentes do ensino superior. Revista Iberoamericana de Educación Superior v.19, n.VII, p. 22-41. 2016. Disponível em http://www.scielo.org.mx/pdf/ries/v7n19/2007-2872-ries-7-1900022.pdf > Acesso em: 25 jun. 2020.

SECOM MACEIÓ. Maceió 198 anos: Entenda essa história. 2013. Secretaria Municipal de Comunicação. Disponível em <http://www.maceio.al.gov.br/2013/12/maceio-198-anos-entenda-essahistoria/> Acesso em: 16 out. 2019.

SEKKEL, Marie Claire. O brincar e a invenção do mundo em Walter Benjamin e Donald Winnicott. Psicol. USP, São Paulo, v. 27, n. 1, p. 86- 
95,

Apr.

2016.

Disponível

em:

<http://www.scielo.br/scielo.php?script=sci_arttext\&pid=So10365642016000100086\&lng=en\&nrm=iso >. Acesso em: 5 ago 2019.

SILVA, Adriana Fraga da. Infância, gênero e brinquedos: reflexões sobre a construção da domesticidade feminina através das coisas contemporâneas de brincar. Revista de Arqueologia, v. 31, n. 2, p. 176196, 28 dez. 2018.

SOUSA, Marilia de Oliveira de; SIRELLI, Paula Martins. Nem santa, nem pecadora: novas roupagens, velhas dicotomias na coisificação da mulher. Serv. Soc. Soc., São Paulo, n. 132, p. 326-345, Aug. 2018 . Disponível em: $\quad$ http://www.scielo.br/scielo.php?script=sci arttext\&pid=S010166282018000200326\&lng=en\&nrm=iso Acesso em: 26 jun. 2020.

SOUZA, Eloisio Moulin de. Fazendo e Desfazendo gênero: a abordagem pós-estruturalista sobre gênero. In: CARRIERE, Alexandre de Padua; TEIXEIRA, Juliana Cristina; NASCIMENTO, Marco Cesar Ribeiro. Gênero e Trabalho: perspectivas, possibilidades e desafios no campo dos estudos organizacionais. perspectivas, possibilidades e desafios no campo dos estudos organizacionais. Salvador: Edufba, 2016. p. 376.

SUMAN, Marcelo. Brinquedo tem gênero?. 2018. 53 f. Monografia (Bacharel em Publicidade e Propaganda). Curso de Publicidade e Propaganda. Universidade de Passo Fundo, Passo Fundo, RS, 2018.

TOLEDO, Renata Ferraz de; JACOBI, Pedro Roberto. Pesquisa-ação e educação: compartilhando princípios na construção de conhecimentos e no fortalecimento comunitário para o enfrentamento de problemas. Educ. Soc., Campinas , v. 34, n. 122, p. 155-173, Mar. 2013 . Disponível em: <http://www.scielo.br/scielo.php?script=sci_arttext\&pid=So10173302013000100009\&lng=en\&nrm=iso >. Acesso em: 15 mai. 2020.

TUZZO, Simone Antoniaci; BRAGA, Claudomilson Fernandes. O processo de triangulação da pesquisa qualitativa: o metafenômeno como gênese. Revista Pesquisa Qualitativa, São Paulo, v. 4, n. 5, p. 140-158, dez. 2016. Disponível em: $<$ https://editora.sepq.org.br/index.php/rpq/article/view/38 $>$. Acesso em: 13 out. 2019. 
VASCONCELLOS, Vera M. R.; SARMENTO, Manuel J. (Orgs.). Infância (in)visível. Araraquara: Junqueira\&Marin, 2007.

VIEIRA, Cristina C. É menino ou menina?: Género e educação em contexto familiar. Coimbra: Almedina, 2006.

WINNICOTT, Donald Woods. Natureza humana. Rio de Janeiro: Imago, 1990.

. Privação e delinqüência. 4. ed. São Paulo: Martins Fontes, 2005.

. O ambiente e os processos de maturação: estudos sobre a teoria do desenvolvimento emocional. 3. Ed. Porto Alegre: Artes Médicas. 2007.

. O brincar e a realidade. Rio de Janeiro, Ubu Editora. 2019.

WHITAKER, Dulce. Mulher e homem: o mito da desigualdade. São Paulo: Moderna, 1988. (Coleção Polêmica)

XIMENES, Verônica Morais et al . Sentimento de comunidade e pobreza rural no nordeste, norte e sul do Brasil. Rev. Subj., Fortaleza, v. 19, n. 1, p. 1-13, abr. $2019 \quad$ Disponível em <http://pepsic.bvsalud.org/scielo.php?script=sci_arttext\&pid=S235907692019000100004\&lng=pt\&nrm=iso > . Acesso em: 27 jun. 2020. 


\section{Children's play in a peripheral community in Maceio-AL city: the gender relations in question}

Knowing the experience of playing and children's games, as well as the sociability networks that (re)produce gender relationships, is relevant for studies on childhood and gender. Therefore, the aim was to analyze stereotypes and gender relations through playful moments with children in preschool. This is an action research with a qualitative approach developed through playful workshops with 20 children between 5 and 6 years old in a peripheral community of maceio city. Content analysis of data from field diaries and children's productions was used. Four thematic categories were created: "beautiful, demure and housewife?"; "is the right to express aggressiveness only for boys?"; "contradictions to gender impositions"; and "the social dimension of the toy". It is concluded that the act of playing reproduces stereotyped roles of gender, which are structured through cultural meanings shared between the groups in which the children belong and pass through a repertoire of what is offered to them as the possibility of toys. However, despite the pre-existence of imposed meanings on gender relations, the creative process of play allows the potential to overcome these crystallized inequalities.

KEYwORDS: Play. Culture. Toys. Gender. Childhood.

Alana Madeiro de Melo BARBOZA

Graduada em Psicologia pela Universidade Federal de Alagoas e Mestranda em Psicologia pela Universidade Federal de Alagoas, na linha "Subjetividades, Políticas e Processos Psicossociais".

Paula Orchiucci MIURA

Professora Adjunta da Graduação e Pós-Graduação do Instituto de Psicologia da Universidade Federal de Alagoas.

Adélia Augusta Souto de OLIVEIRA

Professora permanente do Programa de Pós-graduação e da Graduação em Psicologia, no instituto de Psicologia, Universidade Federal de Alagoas.

Heliane de Almeida Lins LEITÃO

Doutora em Psicologia e Professora do Instituto de Psicologia da Universidade Federal de Alagoas.

Recebido em: 30/06/2020

Aprovado em: 27/01/2021 